\title{
Utilisation of extrusion method in geotechnical tests: conception and theoretical analysis
}

\author{
Masoud S.G. Manafi ${ }^{1}$ (i) $\cdot$ An Deng $^{1} \cdot$ Abbas Taheri $^{2}$
}

Received: 8 November 2021 / Accepted: 15 January 2022 / Published online: 2 March 2022

(c) The Author(s) 2022

\begin{abstract}
Extrusion method has been utilised in a variety of product-processing units such as metal casting and food processing. The process of extruding is relatively fast and reproducible, and more importantly, can benchmark shear resistance of extruded materials. These advantages have propelled researchers to practice the extrusion method to determine soil properties, e.g. Atterberg limits and shear strength. Although the mechanics behind the extrusion process remains less understood, studies have verified the feasibility of the benchmarking. This study presents the theoretical basis underpinning the extruding process by extending the conventional slab analysis method to model the entire process of extruding. The developed analytical method is original in assessing the extrusion of the dead material zone and considering the dynamic move of extruded materials. The novel theoretical analysis enhances a more accurate estimation of extruding pressure and builds a solid foundation for developing extrusion tests in geotechnical engineering. In addition, the described extrusion mechanics explains reasons for observing some discrepant correlations to other geotechnical parameters due to the different soil deformation mechanisms among the test methods.
\end{abstract}

Keywords Soil extrusion $\cdot$ Extrusion pressure $\cdot$ Slab analysis method $\cdot$ Atterberg limits $\cdot$ Shear strength $\cdot$ Laboratory tests

Responsible Editor: Zeynal Abiddin Erguler

Key messages of the paper

- Developing a closed-form analysis method to estimate the extrusion pressure

- Refining the extrusion analysis by modelling the extrusion of dead material zone and considering the acceleration of the extrusion material

- Justifying some discrepant results observed in correlating the extrusion pressures with other conventional tests by interpreting the unique soil deformation mechanism of the extrusion technique

- Highlighting the capability of the extrusion method to become a standalone geotechnical test

Masoud S.G. Manafi

Manafigs@tcd.ie

1 School of Civil, Environmental and Mining Engineering, The University of Adelaide, Adelaide, SA, Australia

2 The Robert M. Buchan Department of Mining, Queen's University, Kingston, Ontario, Canada

\section{Introduction}

The extrusion method is an established technology in manufacturing industry. The industry employs this method to transform (mainly split) raw feed materials into a variety of semi-finished or finished goods, such as cast metals, processed food, remoulded polymers, transformed pharmaceuticals, and packaging materials (e.g. Moscicki 2011; Giles et al. 2004; Guy 2001; Saha 2000; Dieter and Bacon 1988). Although the equipment used by the industrial units are varied to suit different purposes, the concept of extruding remains similar. In essence, a cylindrical extruder is used to house a volume of feed-in materials to drive through an orifice or a die with the aid of a plunger. If the direction of extruding coincides with the movement of the plunger, it is a direct extrusion; otherwise, it is an indirect or reverse extrusion, as demonstrated in Fig. 1. Both extrusions enable the feed-in materials to be compressed, transformed, and remoulded in a defined system.

Albeit not a product by itself, a soil can also be extruded through an orifice. More importantly, the force that drives the process of extruding can be acquired and benchmarked against soil consistency and other soil properties, such as 


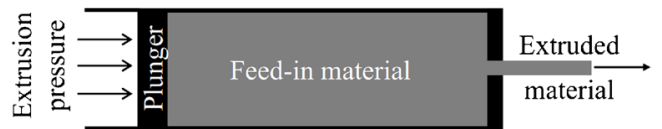

(a)

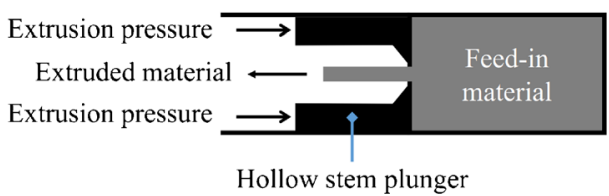

(b)

Fig. 1 Longitudinal cross section of material extruder: a direct method and $\mathbf{b}$ indirect method

shear strength. Timar (1974) was the first who used the direct extrusion to determine soil plasticity. Several years later, Whyte (1982) conducted indirect extrusions and correlated the extruding force with soil consistency limits. Medhat and Whyte (1986) also attempted both the direct and indirect extrusion to determine soil consistency limits and suggested the suitability of utilising the extrusion methods for soil index properties. Kayabali and Tufenkci (2007, 2010) revisited the correlation proposed by Whyte (1982) and extended it based on additional test results they gathered. While they recognised the value of the extrusion technique, they pointed out result discrepancies between extrusion methods and conventional methods. They ascribed the discrepancies to operator dependency of the conventional methods.

Researchers have also extruded soils to determine shear strength. Kayabali and his teams extended their extrusion methods to undrained shear strength (e.g. Kayabali et al. 2015a; Kayabali and Ozdemir 2013; Kayabali 2011) and drained shear strength (e.g. Kayabali et al. 2015b). Extrusion testing has also been applied to special soils, such as high plasticity kaolin-bentonite mixtures (e.g. VerásteguiFlores and Di Emidio 2015; Verástegui-Flores and Di Emidio 2014).

O'Kelly (2019) analysed the results obtained in different studies, aiming to evaluate the suitability of extrusion for soil shear strength determination. He found that the results are diverse between the studies and the consistency is suboptimal. However, the consistency evaluation neglected or at least underestimated the differences in devices, configurations, and soil types between the reviewed studies, which otherwise would have led to a better consistency. Nevertheless, it is expected to observe discrepant results obtained by various methods due to different soil deformation mechanisms.

To enhance the evaluation of the extrusion tests, one solution is to model the process of extruding and normalise it across setups. There is a range of approaches developed to normalise or analyse the process of extruding, such as the uniform energy method (Siebel 1932), slab method (Altan et al. 1983; Hoffman and Sachs 1953), slip-line method (Hill 1998; Dewhurst and Collins 1973; Collins 1968), upperbound method (Johnson and Mellor 1973; Avitzur 1964), and the perturbation method (Spencer 1961, 1962). The finite element methods were also used to simulate extruding processes of various feed-in materials (Argyris and Doltsinis 1979, 1981; Lee et al. 1977). While these analytical and numerical studies demonstrate advantages in mimicking extruding processes, discovering a closed-form solution can provide invaluable insight into the process and outweighs the other approaches (Borwein and Crandall 2013).

This paper aims to gain an insight into the mechanics behind the extruding process by developing a closed-form solution in this regard. The closed-form solution is essential for the soil property determinations using the extrusion method. The accuracy of the soil property determinations can be improved by analysing the force transfer mechanism in the extruder, for instance, by considering the effects of the soil-plunger friction and the extrusion rate on the soil deformation mechanism. Accordingly, equilibrium analyses are conducted, which are based on force, energy, and work relations. The analyses lead to an estimation of extrusion pressure as a function of soil shear strength, extruder configuration, and extrusion rate. The outcomes add to the fabrication and calibration of extruders and likely a broad acceptance of the method by the geotechnical community. It is noteworthy that the current theoretical research is focused on presenting the extrusion method conception and mechanical analysis. This study provides the backbone of further investigations utilising the extrusion method for soil property determinations.

\section{Model development}

The extrusion mechanics depend on multiple factors, such as the physical and engineering properties of extruded materials and the extrusion device's configuration. A typical pattern of material flow in the direct extrusion process is demonstrated in Fig. 2.

A direct extruder model with a single opening is presented in Fig. 3. The extruder has a length of $l_{0}$ and a circular cross section (diameter of $D_{\mathrm{C}}$ and area of $A_{\mathrm{C}}$ ). The circular opening has a diameter of $D_{\mathrm{E}}$ and an area of $A_{\mathrm{E}}$. As $D_{\mathrm{C}}>D_{\mathrm{E}}$, a dead material zone that rests in the inner corner is formed in the process of extruding. As per Saha (2000), the dead material zone has a conical surface with a slope of $\alpha$ and a length of $L_{\mathrm{D}}$. The material in the zone remains stationary until the plunger moves into the zone. Before that, shear between the stationary material and the moving material occurs on the face of the zone. The dead material angle may be determined in 


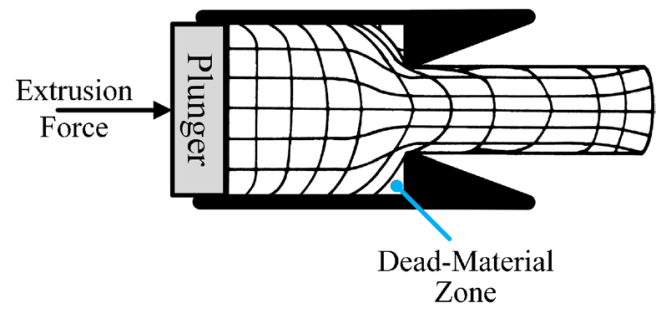

Fig. 2 Schematic pattern of material flow in the direct extrusion method (adopted from Dieter et al. 2003)

practice by studying the etched cross section of dead material after extrusion of the feed-in material prior to extrusion of the dead material (e.g. Saha 2000) or examining the extrusion of material in 2-dimensional laboratory models. Saha (2000) suggested expressing the dead material angle, $\alpha$, as a function of a set of parameters:

$\alpha=f\left(E R, m, m^{\prime}, \bar{\sigma}\right)$

where $E R$ is the extrusion ratio $\left(A_{\mathrm{C}} / A_{\mathrm{E}}\right), m$ is the factor of friction between the material and the inner wall of the extruder, $m^{\prime}$ is the factor of friction on the dead zone surface, and $\bar{\sigma}$ is the flow stress of the material. Flow stress is usually obtained experimentally using uniform compression and torsion tests (Saha 2000) and is a function of strain, $\bar{\varepsilon}$, strain rate, $\dot{\bar{\varepsilon}}$, and soil moisture content, $w$. For the model shown in Fig. 3, considering the material volume consistency, $\bar{\varepsilon}$ and $\dot{\bar{\varepsilon}}$ are defined as:

$\bar{\varepsilon}=\ln \frac{l}{l_{0}}=\ln \frac{A_{\mathrm{C}}}{A_{\mathrm{E}}}$

$\dot{\bar{\varepsilon}}=\frac{\mathrm{d} \bar{\varepsilon}}{\mathrm{d} t}$
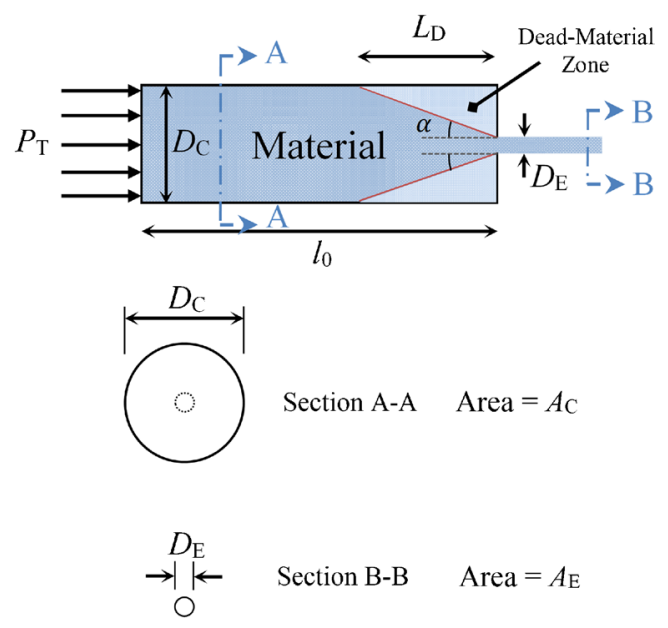

Fig. 3 An extruder model of a single opening direct extrusion

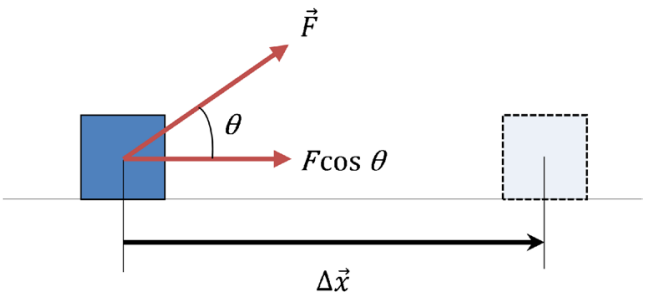

Fig. 4 Illustration for work done on an object by a constant force

where $l$ is the length of the extruded material and $t$ is the time.

The extrusion process consumes energy to counteract resistance forces. Therefore, it is required to define work in physics. The work is exerted if a force is applied to an object leading to a movement by a distance. As shown in Fig. 4 , the work, $W$, done on an object by a constant force, $F$, is calculated as:

$W=(F \cos \theta) \Delta x$

where $\theta$ is the angle between the directions of $\vec{F}$ and $\Delta \vec{x}$, and $\Delta x$ is the displacement magnitude of the gravitational centre points.

Applying the conception of work to the process of extruding in Fig. 5, the total work is calculated as:

$W_{\mathrm{T}}=F_{\mathrm{T}} \Delta x$

The total extrusion pressure can also be calculated as:

$P_{\mathrm{T}}=\frac{F_{\mathrm{T}}}{A_{\mathrm{C}}}$

The total work required for the extrusion of a material can be divided into different sub-works as:

$W_{\mathrm{T}}=W_{\mathrm{D}}+W_{\mathrm{fC}}+W_{\mathrm{fP}}+W_{\mathrm{R}}+W_{\mathrm{Acc}}$

where $W_{\mathrm{D}}$ is the plastic deformation work in the conical deformation zone, $W_{\mathrm{fC}}$ is the material-container walls frictional work, $W_{\mathrm{fP}}$ is the dead material-plunger frictional work, $W_{\mathrm{R}}$ is the redundant work, and $W_{\text {Acc }}$ is the acceleration work. The sub-works can be calculated by analysing the processes of extruding.

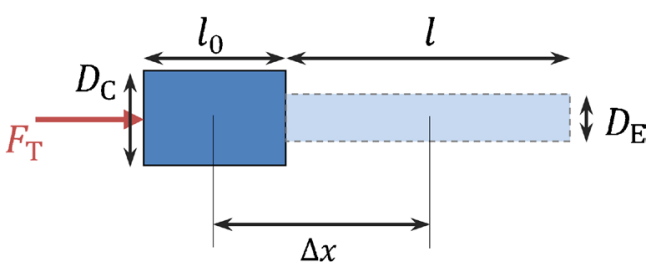

Fig. 5 One-dimensional motion of the extrusion process 
The longitudinal cross section of a direct-method extruder is shown in Fig. 6. In the process of extruding, the feed-in material housed in the extruder is divided into three zones, i.e. the friction, deformation, and dead material zones, respectively. Each zone is represented by a shaded slab. The dead material zone remains relatively static in the extruding process until the plunger has fully passed the friction zone. At this moment, the plunger pushes the dead material zone inward to the deformation zone from the apex to the base of the dead zone. Progressively, the entire volume of material is extruded.

The analyses on the friction and deformation zones are established in the literature (e.g. Saha 2000; Dieter and Bacon 1988) and adopted in this study. This paper presents two updates to the conventional slab analysis method. Consequently, a new model is presented for the extrusion of the dead material zone. In addition, the acceleration of the extrusion material is also considered in the analysis.

The following assumptions are made: (a) a volume of continuous material is extruded through a die; (b) the material is extruded into a rod with a diameter of $D_{\mathrm{E}}$; and (c) frictional shear stress occurs at the interfaces between the dead material and the flowing material, the container and the flowing material, and the plunger and the dead material.

\section{Work to extrude material in deformation zone}

A simplified conical deformation zone is shown in Fig. 6 . The length of the deformation zone, $L_{\mathrm{D}}$, is expressed as:

$L_{\mathrm{D}}=\frac{D_{\mathrm{C}}-D_{\mathrm{E}}}{2 \tan \alpha}$

Fig. 7 shows the element in the deformation zone and stresses acting on the element. The stress equilibrium equation can be written as:

$-\left(p_{\mathrm{Z}}+\mathrm{d} p_{\mathrm{Z}}\right) \frac{\pi(D+\mathrm{d} D)^{2}}{4}+p_{\mathrm{Z}} \frac{\pi D^{2}}{4}+p_{\mathrm{r}} \pi D \mathrm{~d} s \sin \alpha+\tau_{\mathrm{fF}} \pi D \mathrm{~d} s \cos \alpha=0$

where $p_{\mathrm{Z}}$ is the extruding pressure in $\mathrm{Z}$ direction, $D$ is the diameter of the element, $s$ is the slant height of the deformation zone, and $\tau_{\mathrm{fF}}$ is the friction on the interface between the dead material and the flowing material.

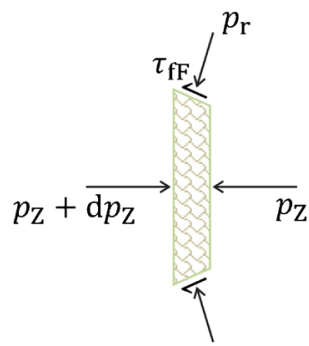

(a)

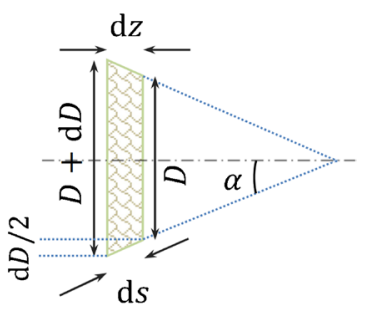

(b)
Fig. 7 Diagrams for the element in the deformation zone: a stress state and $\mathbf{b}$ geometry

Based on the geometry, we have:

$\mathrm{d} s \sin \alpha=\mathrm{d} z \tan \alpha=\frac{\mathrm{d} D}{2}$

$\mathrm{d} s \cos \alpha=\mathrm{d} z=\frac{\mathrm{d} D}{2 \tan \alpha}$

In addition, by applying the Von Mises' yield criterion (Saha 2000):

$p_{\mathrm{r}}=p_{\mathrm{Z}}+\bar{\sigma}$

$\tau_{\mathrm{fF}}=k=\frac{\bar{\sigma}}{\sqrt{3}}$

where $k$ is the material shear strength.

Combining Eq. (9) to Eq. (13) and neglecting higherorder differentials:

$\frac{\mathrm{d} p_{\mathrm{Z}}}{\bar{\sigma}\left(1+\frac{\cot \alpha}{\sqrt{3}}\right)}=\frac{2 \mathrm{~d} D}{D}$

Assuming constant flow stress yields:

$\frac{p_{\mathrm{Z}}}{\bar{\sigma}\left(1+\frac{\cot \alpha}{\sqrt{3}}\right)}=\ln D^{2} C$

where $C$ is the constant of integration and can be eliminated by substitution of the boundary conditions at $D=D_{\mathrm{E}}, p_{\mathrm{Z}}=0$ :
Fig. 6 Longitudinal cross section of a direct-method extruder

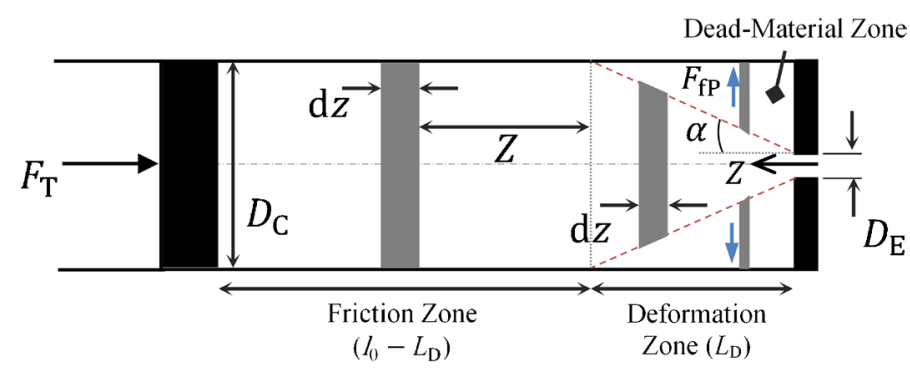


$C=\frac{1}{D_{\mathrm{E}}^{2}}$

The equivalent diameter of the extruded material can also be written as:

$D_{\mathrm{E}}=\frac{D_{\mathrm{C}}}{\sqrt{E R}}$

Therefore, the average extrusion pressure in the deformation zone can be obtained by substitution of the value of the $C$ constant in Eq. (15) as:

$P_{\mathrm{D}}=p_{\mathrm{Z}=L_{\mathrm{D}}}=2 \bar{\sigma}\left(1+\frac{\cot \alpha}{\sqrt{3}}\right) \ln \frac{D_{\mathrm{C}}}{D_{\mathrm{E}}}$

Consequently, the plastic deformation work is obtained as:

$W_{\mathrm{D}}=\left(P_{\mathrm{D}} A_{\mathrm{C}}\right) \Delta x$

\section{Work to extrude material in friction zone}

The work to extrude material in the friction zone, or materialcontainer frictional work, $W_{\mathrm{fC}}$, is required for overcoming the resistance between the container walls and the material. The work is a function of the following parameters:

$W_{\mathrm{fC}}=f\left(p_{\mathrm{r}}, m, m^{\prime}, m^{\prime \prime}, D_{\mathrm{C}}, L, L^{\prime}\right)$

where $p_{\mathrm{r}}$ is the radial pressure, $m^{\prime \prime}$ is the friction factor between the die bearing and the extruded material, $L$ is the material length having the relative movement between the extrusion material and the container walls, and $L^{\prime}$ is the die bearing length, which can be ignored if the die has a relatively small contact area.

The diagram of stress for the element inside the friction zone is shown in Fig. 8. The static equilibrium leads to:

$\left[\left(p_{\mathrm{Z}}+\mathrm{d} p_{\mathrm{Z}}\right)-p_{\mathrm{Z}}\right] \frac{\pi D_{\mathrm{C}}^{2}}{4}=\pi D_{\mathrm{C}} \tau_{\mathrm{fC}} \mathrm{d} z$

where $\tau_{\mathrm{fC}}$ is the frictional shear stress at the material-container interface and can be obtained from Eq. 21. Hence, the

Fig. 8 Diagram of stress for the element inside the friction zone

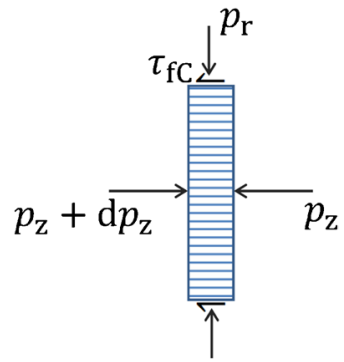

friction force, $F_{\mathrm{fC}}$, at the material-container interface can be obtained as:

$F_{\mathrm{fC}}=\pi D_{\mathrm{C}}\left(l_{0}-L_{\mathrm{D}}\right) \tau_{\mathrm{fC}}$

Accordingly, the extrusion work in the friction zone can be obtained as:

$W_{\mathrm{fC}}=F_{\mathrm{fC}} \Delta x$

\section{Work to extrude material in dead material zone}

The work to extrude material in the dead material zone, or the material-plunger frictional work, $W_{\mathrm{fP}}$, is required for overcoming the sliding resistance between the dead material zone and the plunger. The work is also a function of several parameters and expressed as:

$W_{\mathrm{fP}}=f\left(F_{\mathrm{T}}, m^{\prime \prime \prime}, D_{\mathrm{C}}, L_{\mathrm{D}}\right)$

where $m^{\prime \prime \prime}$ is the factor of friction between the plunger and the dead material, which can be obtained by experiment considering the surface roughness of the plunger-extruding material, rate of extrusion, and normal stresses.

The material in the dead zone remains relatively static during the extruding process and, over time, becomes aged or oxidised where goods are extruded. Hence, industry units usually hold extruding at a safe margin to avoid extruding the dead material (Saha 2000). In this context, the extrusion analysis of the dead material is neglected in industry operations. When adapted for soil property determination, the dead material is extruded out provided it involves no product quality issue within the short period of the tests. In addition, the extruder size is relatively small for soil tests and the complete volume of the specimen is extruded. Therefore, it is required to take account of the dead material zone in the analysis. A simple model is presented in this paper to calculate the pressure required for the extrusion of the dead material zone.

Considering the static nature of the dead material, it is assumed that the plunger forces the dead material into the conical deformation zone by sliding off the material layer by layer from the apex to the base of the dead zone. In addition, it is assumed that the angle of the dead material zone does not change in this process. Therefore, a sliding frictional force is used in the calculations. The assumptions are reasonable considering the relatively faster extrusion of the feed-in material than to the peripheral material in the extrusion of homogeneous materials (Saha 2000).

It is recognised that a portion of the extrusion work is used to transfer the dead material zone into the conical deformation zone. Accordingly, one needs to calculate the vertical movement work of material from the dead zone into the 


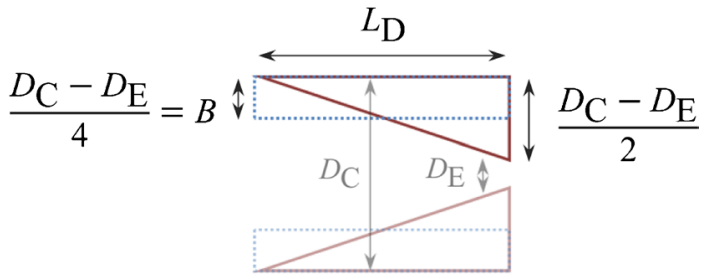

Fig. 9 Longitudinal cross-section of the dead-material zone

conical deformation zone, which comprises part of the total work required for the extrusion. Consequently, the frictional force on the plunger-dead material interface and the displacement of the dead material should be considered. As shown in Fig. 9, the equivalent rectangular area of the triangular dead material zone is developed to simplify the calculations. In this figure, $B$ is the width of the equivalent rectangular area.

As shown in Fig. 10, a string model is proposed to determine the contact area between the dead material and the plunger. The string model replicates the movement of the soil particles into the conical deformation zone. In the course of extruding the dead materials, the boundary elements of the dead material zone are in contact with the plunger. Therefore, the frictional force of the vertical movement of the material in the dead zone can be calculated as:

$F_{\mathrm{fP}}=\tau_{\mathrm{fP}} A_{\mathrm{fP}}=\tau_{\mathrm{fP}} \pi D_{\mathrm{C}} L_{\mathrm{D}}$

where $\tau_{\mathrm{fP}}$ is the frictional shear stress between the dead material and the plunger interface, and $A_{\mathrm{fP}}$ is the contact surface area between the dead material and the plunger.

The work that is required to move the soil material from the dead-zone into the conical deformation zone is calculated as:

$W_{\mathrm{fP}}=F_{\mathrm{fP}} B=\tau_{\mathrm{fP}} \pi D_{\mathrm{C}} L_{\mathrm{D}} \frac{D_{\mathrm{C}}-D_{\mathrm{E}}}{4}$

\section{Extruding work due to mass acceleration}

Extruding work due to mass acceleration, $W_{\text {Acc }}$, leads to acceleration of the material mass. If the extrusion pressure exceeds the pressure required to overcome the internal resistance forces, then the force difference accelerates the soil body in the extrusion process. The acceleration force can be obtained by applying Newton's second law of motion. The force required for acceleration of the material mass can be obtained as:

$F_{\mathrm{Acc}}=m_{\mathrm{s}} a$

where $m_{\mathrm{s}}$ is the soil material mass and $a$ is the material acceleration during the extruding process. Considering the one-dimensional motion of the extrusion process as in Fig. 5, the acceleration of the material is calculated as:

$\Delta x=v_{0} t+\frac{1}{2} a t^{2}=0+\frac{1}{2} a t^{2}=\frac{1}{2} a t^{2}$

$a=\frac{2 \Delta x}{t^{2}}$

where $v_{0}$ is the initial velocity of the soil specimen at the start of extrusion, which is zero at the beginning of the extrusion, and $t$ is the time of extrusion.

Accordingly, the extrusion work pertinent to the acceleration of the material can be obtained as:

$W_{\mathrm{Acc}}=F_{\mathrm{Acc}} \Delta x$

\section{Redundant work in extruding process}

Redundant work, $W_{\mathrm{R}}$, is related to the energy required for internal deformations of the soil material apart from the pure change in the shape of soil material in the extrusion process (Dieter 1961). The work also involves the elastic energy dissipation of the material during the extrusion process. The redundant pressure required for internal deformation work is a function of the flow stress and the angle of the dead-material zone. Considering the general pattern of material flow in the extrusion process as in Fig. 2, shear deformations occur to the elements around the perimeter of the friction zone and on the interface of the dead material zone. In addition, the central elements are under elongation due to the changes in the cross

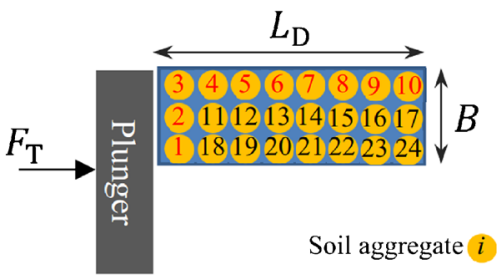

(a)

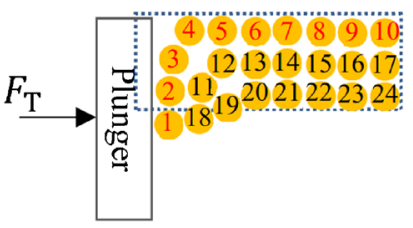

(b)

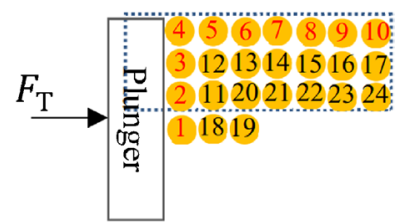

(c)

Fig. 10 A string model for determination of contact area between the dead-material and the plunger: a soil aggregate arrangement at the beginning of the extrusion of the dead-zone, $\mathbf{b}$ and $\mathbf{c}$ progress of sliding aggregates from the dead-zone into deformation cone 
sections. The difference between the calculated extrusion pressure based on the uniform plastic deformation method and the actual exerted extrusion pressure is due to the redundant work during the extrusion process (Saha 2000). The amount of the redundant force is usually determined experimentally or numerically. Alternatively, it is viable to conduct several experiments and determine the redundant work via other subworks as follows:

$W_{\mathrm{R}}=W_{\mathrm{T}}-W_{\mathrm{D}}-W_{\mathrm{fC}}-W_{\mathrm{fP}}-W_{\mathrm{Acc}}$

\section{Discussion}

The extrusion method has been used in several experimental studies for soil property determination, such as Atterberg limit states and different shear strengths (e.g. Kayabali et al. 2016; Kayabali et al. 2015b; Kayabali and Ozdemir 2013). These studies have delivered results of promoting the extrusion method as an alternative test method for the conventional methods. However, data discrepancies are unavoidable in some circumstances. Three reasons might have caused the discrepancies:

1. The inappropriate approach utilised for proposing an alternative test method [i.e. strength-based approach for soil plasticity determination (e.g. Nagaraj et al. 2012)]

2. The variability of the conventional test methods for accurate determination of soil properties (e.g. Manafi 2019)

3. The limited compatibility among the test mechanisms (e.g. different soil deformation mechanisms between the extrusion method and other shear strength tests)

The data discrepancies associated with the incompatibility of different test methods can be explained by analysing the soil deformation mechanisms in the tests. Nevertheless, the mechanics of the extrusion method had not been analysed for rationalising the probable discrepancy related to the difference in the soil deformation mechanisms. This study appears to be the first to cover this gap by proposing a closed-form solution for analysing the soil extrusion technique.

Closed-form solutions are crucial for illustrating the mechanics of methods (Borwein and Crandall 2013; Hassani 2000). Validation or justification of the proposed correlations may be done by synthesising the fundamental components of the soil deformation systems. Consequently, this paper provided an insight into the extrusion mechanics by extending the established slab analysis method (Saha 2000; Altan et al. 1983). The proposed analyses characterise the effective parameters on the soil deformation system in the extrusion technique. As a result, the difference in soil deformation mechanism in the extrusion technique with conventional tests (Head and Epps 2014, 2011; Head 2006) can explain some reasons for a part of the discrepant results obtained in the previous studies (e.g. O'Kelly 2019). In addition, the outcomes of this analysis are beneficial for the performance optimisation of extrusion devices as the effective parameters on soil extrusion are explained in this study.

The effect of material weight can be ignored in the mechanical analysis of the extrusion because the test involves a small volume of material and the weight of the material is relatively negligible compared to the force required for extrusion. However, depending on the design of the apparatus or considerable unit weights of the materials, it might affect the driving force (e.g. in a vertical extrusion) or the radial pressure (e.g. in a horizontal extrusion).

The updates to the slab analysis method presented in this paper involve the slip of soil grains in the dead material zone into the deformation zone and the acceleration of the extrusion material. The parameters introduced in the updates are the same type as the parameters introduced by Altan et al. (1983) in the slab analysis method. Therefore, the reliability and error in parameter measurements remain at the same level as the previously established slab analysis method.

As the soil extrusion analysis revealed, the extrusion pressure is highly affected by the extrusion setup design and the material properties. Although the developed analytical method is presented for soil extrusion tests, it can also be applied to the general extrusion process using various feed-in materials. This paper also proposed a method for calculating the extrusion pressure that may be used for adopting proper actuators in designing and calibrating new apparatuses.

Considering the mechanics of the extrusion method explained in this paper, this method provides a unique soil deformation system that may serve as a novel test method for reliable and reproducible soil property determinations. For instance, the comprehensive soil deformation process in the extrusion process may be used to study the consistency of cohesive soils based on the definition of soil consistency, "the relative ease with which a soil can be deformed" (ASTM D653-14 2014). Additionally, the soil extrusion technique can be utilised to study special geotechnical cases such as mud-rush or running soft geo-materials into underground structures. In other words, though the extrusion method can be used as an alternative method to conventional methods, it is greatly capable of introducing new standalone test methods for soil property determinations.

Although a few researchers provide considerable data on soil extrusion, little information about the details of apparatus fabrication/specification, soil sampling/specimen preparation, and test procedure are provided. Furthermore, just a few cohesive soil types with different minerals are 
investigated. Therefore, the knowledge of the extrusion method in geotechnical engineering is not fully established. Hence, it is required to conduct comprehensive research studies to establish the extrusion method for soil property determinations.

Considering the mechanism of soil deformation in the extrusion process, various inter-related parameters (e.g. $m^{\prime}, \alpha, \bar{\sigma}, \tau_{\mathrm{fC}}, \tau_{\mathrm{fP}}$ ) affect the extrusion pressure. The parameters' values depend on the device geometry, extrusion rate, plunger, mould, and feed-in material properties. Assessment of the effective parameters on the soil extrusion requires separate comprehensive experimental studies fabricating extrusion devices with sophisticated instrumentations that are out of this paper's scope. The logistic limitations prevented the authors from further practical investigations in this regard. In addition, the previous studies have not provided parameters' values and apparatus specifications to validate the conventional and the refined slab analysis methods for soil extrusion. However, this research theoretically extended the conventional slab analysis method, which builds a solid foundation for further studies on this topic.

Soil extrusion method has several advantages over the conventional geotechnical test methods such as (e.g. Kayabali et al. 2016; Kayabali 2012; Medhat and Whyte 1986; Timar 1974):

- Being quick and repeatable test with low operator dependency and high reliability

- Simple and relatively inexpensive fabrication of the apparatus depending on the setup design

- Requiring a low volume of a soil sample

- Capability to investigate different material properties with one apparatus and test procedure

Therefore, developing new test methods based on the extrusion technique would greatly benefit geotechnical engineering practice.

\section{Conclusions}

Recently the extrusion method has been used as an alternative method to determine soil properties such as Atterberg limits and soil shear strength (e.g. Kayabali et al. 2016; Kayabali et al. 2015b; Kayabali and Ozdemir 2013). Some of the discrepant results observed by the extrusion and standard methods may be due to the different soil deformation mechanisms among the apparatuses. Consequently, the mechanics of the extrusion technique is discussed in this paper, aiming to gain a further understanding of the extrusion process and explaining some reasons for observing discrepant results with the conventional methods. This paper extended the established closed-form analysis method developed for the estimation of the extrusion pressure (Saha 2000; Altan et al. 1983). Accordingly, a new model was developed to interpret the extrusion of the dead-material zone. In addition, the acceleration of the material during the extrusion process was taken into account to refine the calculation of the extrusion pressure. The current study was limited to the theoretical analysis of the soil extrusion technique; however, the results provide a significant first step towards further experimental investigations leading to a broad acceptance of the extrusion method in geotechnical engineering.

This paper provided an insight into the extrusion technique and explained the mechanisms involved in the extrusion process. Consequently, the discrepancies observed in previous studies related to the limited compatibility among the test methods are justified in terms of the different soil deformation mechanisms. The outcomes are also crucial for designing new extrusion test equipment.

Several researchers have stated that the soil extrusion method can examine soil properties with low operator dependency and high reproducibility (e.g. Kayabali et al. 2016, Kayabali 2012, Medhat and Whyte 1986, Timar 1974). The independent soil deformation mechanism of the extrusion method explained in this paper supports their statements if the apparatuses are well designed and fabricated. These advantages enable the extrusion method to become a prominent standalone test method as well as acting as an alternative test method to the conventional tests. Therefore, the authors recommend comprehensive investigations on this topic to reach reliable and reproducible results in soil property determinations.

Notations $a$ : acceleration of the material during the extrusion process; $A_{\mathrm{C}}$ : cross-sectional area of container; $A_{\mathrm{E}}$ : cross-sectional area of extruded material; $A_{\mathrm{fp}}$ : contact surface area between the dead-material and the plunger; $B$ : width of the equivalent rectangular area of the triangular dead-material zone; $D$ : diameter; $D_{\mathrm{C}}$ : equivalent diameter of the container; $D_{\mathrm{E}}$ : equivalent diameter of the extruded material; $E R$ : extrusion ratio; $\vec{F}$ : force vector; $F$ : magnitude of force; $F_{\text {Acc: }}$ force required for acceleration of the material mass; $F_{\mathrm{fC}}$ : frictional force at the material-container interface; $F_{\mathrm{fP}}$ : frictional force of vertical movement of the material in the dead-zone; $F_{\mathrm{T}}$ : total extrusion force; $k$ : material shear strength; $l$ : final length of extruded material; $L$ : material length having the relative movement between the extrusion material and the container walls; $L^{\prime}$ : die bearing length; $l_{0}$ : initial length of extrusion material; $L_{\mathrm{D}}$ : length of the dead-material or deformation zones; $m$ : factor of friction between the interface of the material and the container; $m^{\prime}$ : factor of friction at the dead-material zone and the flowing material interface; $m^{\prime \prime}$ : friction factor between the extruded material and the die bearing; $m^{\prime \prime \prime}$ : friction factor between the plunger and dead-material zone; $m_{\mathrm{s}}$ : mass of the soil material; $P_{\mathrm{D}}$ : pressure required for the plastic deformation of the material; $P_{\mathrm{fC}}$ : pressure required to overcome frictional resistance between the material and the container walls; $p_{\mathrm{r}}$ : radial pressure; $P_{\mathrm{T}}$ : total extrusion pressure; $p_{\mathrm{Z}}$ : extrusion pressure in $\mathrm{Z}$ direction; $s$ : slant height of deformation cone; $t$ : time; $v_{0}$ : initial velocity of soil specimen at the start of extrusion; $w$ : soil water content; $W$ : work; $W_{\text {Acc }}$ : work required for the acceleration of the 
material mass; $W_{\mathrm{D}}$ : plastic deformation work of the material inside the conical deformation zone; $W_{\mathrm{fC}}$ : work required to overcome frictional resistance between the material and the container walls; $W_{\mathrm{fp}}$ : work required to overcome sliding resistance between the dead-material zone and the plunger; $W_{\mathrm{R}}$ : redundant work; $W_{\mathrm{T}}$ : total extrusion work; $\vec{x}$ : displacement vector; $\alpha$ : angle of the dead-material zone; $\Delta x$ : magnitude of the displacement; $\theta$ : angle between the directions of $\vec{F}$ and $\Delta \overrightarrow{\mathrm{X}}, ; \bar{\sigma}$ : flow stress; $\tau_{\mathrm{fF}}$ : frictional shear stress at the dead-material zone and the flowing material interface; $\tau_{\mathrm{fC}}$ : frictional shear stress at the material-container interface; $\tau_{\mathrm{fp}}$ : frictional shear stress between the dead-material and the plunger interface; $\bar{\varepsilon}$ : natural strain; $\overline{\bar{\varepsilon}}$ : strain rate

Acknowledgements The first author kindly acknowledges a postgraduate research scholarship (ASI) received from the University of Adelaide.

Funding Open Access funding enabled and organized by CAUL and its Member Institutions.

\section{Declarations}

Conflict of interest The authors declare that they have no competing interests.

Open Access This article is licensed under a Creative Commons Attribution 4.0 International License, which permits use, sharing, adaptation, distribution and reproduction in any medium or format, as long as you give appropriate credit to the original author(s) and the source, provide a link to the Creative Commons licence, and indicate if changes were made. The images or other third party material in this article are included in the article's Creative Commons licence, unless indicated otherwise in a credit line to the material. If material is not included in the article's Creative Commons licence and your intended use is not permitted by statutory regulation or exceeds the permitted use, you will need to obtain permission directly from the copyright holder. To view a copy of this licence, visit http://creativecommons.org/licenses/by/4.0/.

\section{References}

Altan T, Oh S-I, Gegel HL (1983) Metal forming: fundamentals and applications. $\mathrm{OH}$, American Society for Metals, Metals Park

Argyris JH, Doltsinis JS (1979) On the large strain inelastic analysis in natural formulation part I: quasistatic problems. Comput Methods Appl Mech Eng 20(2):213-251. https://doi.org/10. 1016/0045-7825(79)90020-3

Argyris JH, Doltsinis JS (1981) On the natural formulation and analysis of large deformation coupled thermomechanical problems. Comput Methods Appl Mech Eng 25(2):195-253. https://doi. org/10.1016/0045-7825(81)90084-0

Astm D653-14 (2014) standard terminology relating to soil, rock, and contained fluids. ASTM International, West Conshohocken. https://doi.org/10.1520/D0653-14

Avitzur B (1964) Analysis of wire drawing and extrusion through conical dies of large cone angle. J Manuf Sci Eng 86(4):305314. https://doi.org/10.1115/1.3670543

Borwein JM, Crandall RE (2013) Closed forms: what they are and why we care. Not Am Math Soc 60:50-65. https://doi.org/10.1090/noti936

Collins IF (1968) The algebraic-geometry of slip line fields with applications to boundary value problems. Proc R Soc A: Math Phys Eng Sci 303(1474):317-338. https://doi.org/10.1098/rspa. 1968.0053
Dewhurst P, Collins IF (1973) A matrix technique for constructing slip-line field solutions to a class of plane strain plasticity problems. Int J Numer Methods Eng 7(3):357-378. https://doi. org/10.1002/nme.1620070312

Dieter GE (1961) Mechanical Metallurgy. McGraw-Hill, New York

Dieter GE, Bacon D (1988) Mechanical metallurgy, SI metric edn. McGraw-Hill, Singapore

Dieter GE, Kuhn HA, Semiatin SL (2003) Handbook of workability and process design. ASM International, Materials Park

Giles HF, Mount EM, Wagner JR (2004) Extrusion: the definitive processing guide and handbook. Elsevier Science, Houston

Guy RCE (2001) Extrusion cooking: technologies and applications. Woodhead, Cambridge

Hassani S (2000) Mathematical methods: for students of physics and related fields. Springer, New York

Head KH (2006) Manual of soil laboratory testing, Volume 1: Soil Classification and Compaction Tests. Whittles Publishing, Scotland

Head KH, Epps RJ (2011) Manual of Soil Laboratory Testing, Volume 2: Permeability, Shear Strength and Compressibility Tests, 3rd edn. Whittles Publishing, Scotland

Head KH, Epps RJ (2014) Manual of Soil Laboratory Testing, Volume 3: Effective Stress Tests, 3rd edn. Whittles Publishing, Scotland

Hill R (1998) The mathematical theory of plasticity. Oxford University Press, Oxford

Hoffman O, Sachs G (1953) Introduction to the theory of plasticity for engineers. McGraw-Hill, New York

Johnson W, Mellor PB (1973) Engineering plasticity. Van NostrandReinhold, London

Kayabali K (2011) Assessment of Shear Strength at Consistency Limits - a Reappraisal. Electron J Geotech Eng 16(U):1679-1695

Kayabali K (2012) Estimation of liquid, plastic and shrinkage limits using one simple tool. Electron J Geotech Eng 17(N):2079-2090

Kayabali K, Ozdemir A (2013) Use of reverse extrusion method to determine undrained shear strength. Geotech Geol Eng 31(2):719-727. https://doi.org/10.1007/s10706-013-9621-y

Kayabali K, Tufenkci OO (2007) A different perspective for the determination of soil consistence limits. In: In International Symposium on Geotechnical Engineering. Ground Improvement and Geosynthetics for Human Security and Environmental Preservation, Bangkok, pp 423-432

Kayabali K, Tufenkci OO (2010) Determination of plastic and liquid limits using the reverse extrusion technique. Geotech Test $\mathbf{J}$ 33(1):1-9. https://doi.org/10.1520/GTJ102209

Kayabali K, Aktürk Ö, Fener M, Dikmen O, Harputlugil FH (2015a) Revisiting the Bjerrum's correction factor: use of the liquidity index for assessing the effect of soil plasticity on undrained shear strength. J Rock Mech Geotech Eng 7(6):716-721. https:// doi.org/10.1016/j.jrmge.2015.07.003

Kayabali K, Yilmaz N, Mollamahmutoglu M (2015b) An Alternative Shear Strength Test for Saturated Fine-Grained Soils: Preliminary Results. IOS Press, Buenos Aires. https://doi.org/10.3233/ 978-1-61499-601-9-407

Kayabali K, Aktürk Ö, Fener M, Ozkeser A, Ustun AB, Dikmen O, Harputlugil F, Asadi R (2016) Determination of Atterberg limits using newly devised mud press machine. J Afr Earth Sci 116:127-133. https://doi.org/10.1016/j.jafrearsci.2016.01.005

Lee EH, Mallett RL, Yang WH (1977) Stress and deformation analysis of the metal extrusion process. Comput Methods Appl Mech Eng 10(3):339-353. https://doi.org/10.1016/0045-7825(77) 90077-9

Manafi MSG (2019) Soil plasticity variability and its effect on soil classification. Geotech Test J 42(2):457-470. https://doi.org/ 10.1520/GTJ20170273 
Medhat F, Whyte I (1986) An appraisal of soil index tests. Geol Soc London Eng Geol Special Publ 2(1):317-323. https://doi.org/ 10.1144/GSL.1986.002.01.55

Moscicki L (2011) Extrusion-Cooking Techniques: Applications, Theory and Sustainability. Weinheim, Wiley-VCH; Chichester: John Wiley.

Nagaraj HB, Sridharan A, Mallikarjuna HM (2012) Re-examination of undrained strength at Atterberg limits water contents. Geotech Geol Eng 30(4):727-736. https://doi.org/10.1007/ s10706-011-9489-7

O'Kelly BC (2019) Reappraisal of soil extrusion for geomechanical characterisation. Geotech Res 6(4):265-287. https://doi.org/10. 1680/jgere.19.00006

Saha P (2000) Aluminum Extrusion Technology. Materials Park, ASM International

Siebel E (1932) Metal Forming in Plastic Condition (in German). Verlag Stahieisen, Düsseldorf

Spencer AJM (1961) Perturbation methods in plasticity-I plane strain of non-homogeneous plastic solids. J Mech Physics
Solids 9(4):279-288. https://doi.org/10.1016/0022-5096(61) 90005-9

Spencer AJM (1962) Perturbation methods in plasticity-II plane strain of slightly irregular bodies. J Mech Physics Solids 10(1):17-26. https://doi.org/10.1016/0022-5096(62)90025-X

Timar A (1974) Testing plastic properties of cohesive-type and intermediate-type soils by extrusion. Acta Tech Acad Scientiarum Hungaricae 76(3-4):355-370

Verástegui-Flores RD, Di Emidio G (2014) Assessment of clay consistency through conventional methods and indirect extrusion tests. Appl Clay Sci 101:632-636. https://doi.org/10.1016/j.clay. 2014.09.033

Verástegui-Flores RD, Di Emidio G (2015) Determination of consistency limits of clay by means of extrusion tests. In: In Proceedings of European Conference on Soil Mechanics and Geotechnical Engineering, 3rd edn. ICE, Bristol, pp 3431-3436. https:// doi.org/10.1680/ecsmge.60678.vol6.538

Whyte IL (1982) Soil plasticity and strength - a new approach using extrusion. Ground Eng 15(1):16-18 20, 22, 24 